DOMINATION AND DEPENDENCE IN MASS COMMUNICATIONS:

IMPLICATIONS FOR THE USE OF BROADCASTING IN DEVELOPING COUNTRIES*

Rita Cruise O'Brien **

Introduction

'Cultural patterns once established are endlessly persistent. The opportunity to freshly mould a new nation's outlook and behaviour is historically unique and merits most careful deliberation. Yet in modern mass communications hard and inflexible laws - economic and technological - operate. If these are not taken into account in the beginning and at least partially overcome, courses of development automatically unfold that soon become unquestioned "natural patterns".' (Schiller, 1969).

Schiller's book represents a considerable departure from much of the literature on communications and development produced (mainly in the United States) in the 1950s and 1960s. Its important contribution is to force us to consider the problem in an international context.

Until recently, the concern of scholars working on the media and development has been exclusively with media in the national context accepting without significance that technologies and systems were almost exclusively imported. They took as a basic assumption that technologies were culturally neutral. Such work concentrated on monitoring individual response to the new stimulus of the mass media, regarding the process itself as an unquestioned catalyst of social change and, therefore, development. Such constructs as 'empathy', a capacity to identify with new aspects in the environment, (Lerner, 1958) or 'diffusion' of exogenously produced change (Rogers and Svenning, 1969) left unquestioned a series of assumptions about cultural patterns and the national or international context of such changes. Such approaches have recently been called severely to question for their ahistorical view of development, their

\footnotetext{
* Many of the arguments contained in this article were prepared for the International Broadcast Institute as a Research Programme in June 1974.

** Rita Cruise O'Brien is a Fellow of the Institute of Development Studies.
} 
notion of psychological take-off, and their middle-class idealization of individual mobility (Golding and Elliot in E.J. de Kadt, ed. 1974). Through this criticism of the uses of mass communications and the nature of the development process it becomes possible to pose a new set of issues.

If one accepts that the mass media consist basically of (a) 'the technologies employed by industrial organizations for the production and transmission of message systems in quantities obtainable only by mass production and rapid distribution techniques', and (b) that media technology and systems 'can act as the chief cultural arm of the industrial order from which they originate' (Gerbner in Halmos, ed. 1969), how much non-technical dependence goes along with the transmission of this technology? This depends in part on the medium (less with sound broadcasting than television, for example), on the type of contract negotiated for the use of the system and on the actual (contrasted with formally stated) uses to which it is put. Few LDC importers of media technology are in a position to compete technically with the 'hardware' that is available from the rich countries, or the volume of low cost imported programmes ('software') particularly for television. What capacity the importing culture has to use the system for its own purposes, rather than just become a receiving agent depends on a number of factors. Some years ago it was a typical reflex for developing countries in Asia and Africa particularly to accumulate more and more sophisticated 'hardware' for prestige purposes on the assumption that these could be used for unification and development in the national interest. Attractive packages were sold by skilful media exporters and whole systems installed before it became apparent that there were few facilities available for making all but the most rudimentary television programmes locally - so the one-way 'free flow' was established. There is now renewed consideration of choices of systems, and the uses of radio and television.

This article will consider mass communications and under-development in the international context through examining the nature of the domination established in the field by major international firms, and the resulting dependence within which policy-makers in developing countries make choices about the uses of broadcasting systems for development. It will consider the 
constraints and possibilities of the world market in respect of technologies, equipment and programmes and their reinforcement through patterns of training. Such an examination is predicated on the assumption that to demonstrate the nature of the constraints will develop an awareness among those who are making communications policies for developing countries in order that they may be less dependent on existing structures and markets. Thus, it is assumed that they will be better able to exploit the potential of various media for national and regional development. ${ }^{1}$

\section{Flow of Information}

It has been widely observed that an important aspect of the relations between developed and developing countries is the flows of information between them. This communications process tends to be dominated by a one-way flow of information from technologically advanced metropolitan centres, diffused outward through newspapers, radio, television and films at a popular level, or professional journals and international conferences at a more professional level. Each technological improvement which accelerates the process of diffusion tends to reinforce this one-way flow and renders it more difficult to redress the balance.

There is a quantitatively important flow of information from developing countries to the metropolitan centres on markets and strategic and political issues, which merely reflects the power of control and selection of information at the centre for its own purposes. Rarely is there more than a trickle of indigenously conceived information about developing societies diffused through the mass media in developed countries. Recent studies have documented the dominant flows in terms of international news

\footnotetext{
${ }^{1}$ A number of people have been of considerable assistance in the preparation of the present piece, in particular Asa Briggs and Ed Ploman for the IBI. Stuart Hood, Professor of Radio and Television at the Royal College of Art, Brian Kirby, Director of Broadcasting, Centre for Educational Development Overseas, Peter Golding, Centre for Mass Communications, University of Leicester, and Mick Pilsworth, Research Associate IBI-Ford project on Broadcasting for National Development have all commented on the manuscript at various stages. I am also grateful for the thorough discussions with numerous members of IDS Research Committee and with my husband, Donal Cruise O'Brien.
} 
agencies $^{2}$ and the diffusion of television programmes ${ }^{3}$, and have confirmed the trend from the centre outward. This trend is situated in the broader framework of increasing control of information and information retrieval systems by major international firms and governments. Flows to developing countries consist of knowledge and technologies developed at the centre for which there is limited access to their production.

The flow of radio, television and film material should be considered in the context of more general information flows to understand the difficulties which less developed countries face in trying to redress the balance. A number of countries, including Kenya, Nigeria and Morocco, are trying to reduce the number of imported television programmes diffused on their national networks. Some regional broadcasting unions, notably the Arab States Broadcasting Union, have begun to initiate a closer regional interchange of programmes to counteract the market dominance of exporters like the major US networks through their overseas subsidiaries. New types of equipment such as video casettes offer very important possibilities for flexibility and localization of programmes.

Many difficulties must be faced however, most notably perhaps the considerably greater cost of producing local television programmes rather than importing them. This problem of relative cost is considerably aggravated by the fact that many of the recently established stations are compatible in colour. The unquestioned striving for continuous broadcasting once a television station has been established ${ }^{4}$ makes the reservoir of relatively cheap imported programmes, often marketed in packages by the major firms, nearly the only sources of material. Produced originally for American

2 Oliver Boyd-Barrett, at the City University, London, work in progress.

${ }^{3}$ Work on the sources of imported TV programmes and the mechanism or channels of their sale and exchange is currently being done for UNESCO in Finland. It elaborates some of the problems raised by Schiller (Varis,1973). This is the first attempt to look systematically at the impact of the international marketing system. From this excellent groundwork, much more can be done on the organization of the market itself.

${ }^{4}$ Elihu Katz takes issue with the aim of continuous broadcasting for developing countries and has questioned its advisability (Katz in Gerbner et al. eds. 1973). 
non-stop broadcasting, out of date serials and films which are no longer useful for the domestic market can be sold in bulk to developing countries.

Programme flows can be divided into a series of categories, principally news, entertainment and documentaries and their sub-categories, in order to obtain an adequate picture of total flows. At the moment there seems to be a heavy preponderance of entertainment programmes in the flow of television material to LDCs, which assume a mass audience and levelling of tastes, to the near exclusion of news and documentary programmes. These flow patterns assume a passive audience which receives rather than responds to a medium which has great potential for an interchange of information within the country itself. Therefore at a time when television in some developed countries is beginning to establish a more effective two-way flow between audience and producing agency, in developing countries the major part of the 'diet' is material derived from another culture and produced originally with another audience in mind.

Entertainment programmes exported to developing countries contain considerable implicit information about the values and life styles of the inhabitants of rich countries which may encourage aspirations among audiences in developing countries that are difficult to satisfy ${ }^{5}$. These programmes may provide the possibility for emulation and luxury spending among an elite group, but they produce frustration among those who are less fortunate. The diet of imported programmes may not cause this split, but its content serves to reinforce many other influences in the society which provide the opportunity for taste transfer and life styles derived from rich countries. Imported television programmes may also contain normative assumptions about development which may support dominant national priorities or, as is more frequently the case, may be a persuasive counterweight to these priorities.

\footnotetext{
5 There is potentially a very important area for research here which could be done on the basis of content analysis. Although much work exists on socialization and television viewing and on the effects of violence in television on children, no work to date considers the effects of a substantial diet of imported American entertainment programmes on cultures as varied as Ethiopia and Brazil.
} 
When television is available to a large number of people as in some Latin American countries for example, the effects of levelling tastes and creating a mass audience on the American model are considerable. It must be said that except in Latin America, the levelling of tastes which imported programmes support is rather an assimilation of imported tastes and consumer demands by a small and wealthy section of the population. Thus in Asia and Africa, for example, where television serves a relatively restricted group of the elite (because the cost of receivers is considerable), their taste for entertainment, and as in the recent case in Bombay their vocal defence of imported programmes, may serve to reinforce their links with a transnational elite. Recent research has suggested that there is a declining market for big programme exporters such as the US companies, but once imported tastes are established, local concerns may be compelled to follow former models, and produce programmes like the telenovellas modelled on American soap operas which dominate Latin American broadcasting time. To what extent the model of Latin American television tastes and structures will be a model for other regions in the future is a question which anyone concerned with the future of mass communications in Asia and Africa must confront.

\section{Multinational Corporations and the Media}

Since 1945, there has been an increasing rise in the power and effectiveness of multinational corporations in mass communications, as in other fields. A number of factors have contributed to this increased domination.

1. Major multinational firms were able to intensify the level of traditional market competition by extending its range and changing its form. They were assisted in consolidation by the sophistication of the technologies, the high cost of equipment, and their capacity to buy relevant expertise out of the competitive market. As national firms were superseded by multinationals, this had considerable effects on pricing mechanisms and the availability of technologies. Above all, the consolidation of interlocking interests under the rubric of an international conglomerate assisted them in establishing efficient control of information about markets and distribution mechanisms. Empirical study may reveal differences in approach and 
operation among firms which market equipment, those which market programmes and those which operate subsidiaries in both fields.

2. Pricing is one of the principal instruments of dominance of multi national firms. Television was developed primarily as a commercial medium in contrast to the earlier establishment of radio outside North and South America. Assisted by the expansion of advertising agencies, the interests of consumer goods industries in the developed countries and their overseas subsidiaries gave a considerable boost to the establishment of television, particularly in Latin America ${ }^{6}$. Once film and television material was produced for the mass market in developed countries it could be marketed internationally at a relatively low cost since the marginal cost of production (an extra reel of film or videotape) was so low.

3. Another mechanism for creating dominance is the technical standards constraints operated by multinational corporations, including intra-firm systems, which require that all a firm's equipment be fitted only with their particular spare parts, supplied through their subsidiaries. Patents may be used to block dual markets by requiring that only a certain type of film can be used in a specific camera. The known incompatability of the main colour television systems and of various videotaping systems present those making decisions about imports for broadcasting with a dilemma. Increasing the range of choice and thereby decreasing dependence on a particular source of technology may be an expensive project requiring duplication of equipment. Decisions concerning the adoption of national standards systems for a range of broadcasting equipment can be very difficult, with several major firms vying for a monopoly position.

4. Perhaps more important than pricing or technological control has been the marketing mechanism itself. Whole packages of equipment and programmes have been offered to new television stations, including even the studio and transmitter in exchange

\footnotetext{
${ }^{6}$ The relationship between advertising agencies and the development of broadcasting is examined in J. Tunstall's book, The Anglo-American Media in the World, London, forthcoming.
} 
for certain tied contracts. Large firms like Phillips and Thomson International Enterprises have been in a position to provide personnel to get a system started, and training to work their systems. They then handle the distribution of programmes and the international marketing side including attraction of advertising to the station. The management-contractor operations of firms like TIE in the Caribbean as elsewhere merit careful scrutiny, particularly with a view to explaining the prospects and difficulties of converting such packages for better local use ${ }^{7}$. In the last decade, the competition of Japanese firms in the hardware market has been considerable, and the types of contracts negotiated by major Japanese firms should be examined.

The exploitation of the market through such commercial packages, including expertise, software and training, is perhaps a first phase in the establishment of the hegemony of the multinational corporation in the LDC market. A second phase, which is already operative in Latin America, is the purchase of all or part interest in local networks, which permits the possibility of greater control. In countries like Brazil legal alteration has been made to accommodate US investment, despite the constitutional provision which prohibits foreign ownership of the national communications installations.

\section{Institutional Transfers and Present Organizational Structures}

The institutional forms of broadcasting found in the majority of developing countries reflect to a greater or lesser degree the direct transfer of institutional forms from metropolitan countries. An administration itself may impose a considerable constraint on the more effective use of broadcasting for the purpose of national development ${ }^{8}$.

\footnotetext{
${ }^{7}$ For a vigorous critique of their operations in Guyana and other Caribbean countries, see C. Nasamiento, 'The Menace of the Mass Media' The New Internationalist, September 1973.

${ }^{8}$ Research is underway to examine the promise and performance of broadcasting organizations in selected developing countries. E. Katz and G. Wedell, 'The Role of Broadcasting in National Development', for the Ford Foundation and the International Broadcast Institute.
} 
The main broadcasting organizations in France, Britain and the USA, provided models of operation or were directly responsible for setting up transmission, supplying equipment, and personnel to many developing countries. There are, of course, two separate modes of transfer here, one commercial and one institutional. The similarities and differences between these modes of transfer are important, as well as the various philosophies inherent in these patterns of transfer. Organizations like the BBC and ORTF, NBC and CBS exported not only their structures but their philosophies of operation, the traces of which remain in varying degrees in Africa, Asia and Latin America. These traces are reinforced through continued transfers of personnel, training forms and imported programmes or programme types.

Four questions must be asked in the context of transfers:

(i) To what extent do the transfers represent the unhindered penetration of the international market into the national economy?

(ii) How well adapted were the organizations of broadcasting for transfer from one cultural environment to another?

(iii) What were the cultural and political assumptions underlying the kind of institutions transferred?

(iv) How did the organizations fit into and affect the bureaucratic structures of the recipient countries?

Changes in the organizational location of broadcasting in the national bureaucratic system of developing countries has often followed a pattern of the public corporation giving way to greater state control (especially in Africa) with considerable implications for the role of broadcasting and professional broadcasters. In whatever organizational form, the extent to which the formal goals of the organization may have been undermined by the nature of the bureaucratization process itself is important. Has the administration of broadcasting sapped the potential of the media for creative response to the needs of the society or specialized groups?

Certain broadcasting authorities have gone through considerable vicissitudes with the changes in the style, control and ideology of the national ruling group. An excellent example of this is Cuba, which from being one of the most absorptive models of North American 
influence in the area has become one of the most original in using the mass media almost exclusively for goals of national education and development. Another interesting example is the Ghanaian Broadcasting Corporation which has had widely different emphases through contrasting styles of government in the last decade ${ }^{9}$.

Co-ordination between communications sub-systems in developing countries is often partial and rarely integrated, as for example, in the relationship between educational and general broadcasting. Educational broadcasting often commands a low priority in terms of talent and effort in many national broadcasting organizations. In order to establish the reason for this one could examine the salaries, recruitment and career structures in both education and broadcasting and make some suggestion as to how they could be better co-ordinated for better use of talent.

Training, Professionalism and the Transfer of Technology

The perpetuation of a particular organizational structure which may have been derived from an imported model can often be assured by the nature of professionalism in the organization and the type of training which it supports. Training is, of course, in timately linked to the types of technologies which may be imported and developed for uses in broadcasting. Constraints on the uses of broadcasting may exist since its inception or may have been centred in types of equipment and training initiated at that time or through various packages grafted onto the system.

The process of professionalization in broadcasting may itself have introduced a new constraint resistant to changes in the organizational structure. For this reason, there may have been alternative technologies which were not initially considered or new forms of training which depart from the manner in which the first generation of technicians, managers, producers and cameramen were trained. There seems no better way of protecting broadcasting training than arguing against changes which would 'lower professional standards'. Amongst changes which have been suggested are altering recruitment

\footnotetext{
${ }^{9}$ This has been outlined in a brief pilot enquiry done by my colleague, Robin Luckham, in April 1974.
} 
policies to reduce the necessity for secondary school examination results for entry into training courses, and tapping some of the natural mechanical, acting or presentational talent required for work in broadcasting. Other changes would include despecialization and the introduction of polyvalent training, course content based directly on current demands of the organization rather than on established standards ${ }^{\mathbf{1 0}}$.

Training goals must be considered in the context of national priorities and the scope and activities of the broadcasting organizations under examination. BBC and BBC-type programmes which have been dominant in English-speaking Africa, for example, seem to have increased the number of people trained in various specialisms without questioning basic aims. A new influence on training and personnel systems in Africa, (Ethiopia for example) has been the commercial television 'package' which aims to train a minimum of people to run a station as cheaply as possible and ensure a profit.

Until now, regional training courses in Asia and Africa have been organized and staffed almost exclusively by international organizations or bilateral aid agencies. Local broadcasting authorities themselves might initiate regional training courses which could have a very fruitful spin-off for encouraging professional interchange among countries. Among the difficulties of achieving greater regional interaction may be the non-transferability of different technologies used by various national systems, (although ex-colonies of a single metropolitan power in some circumstances might build from metropolitan standardization here).

Professionalism itself may be a considerable constraint on rethinking priorities for broadcasting. Engineers and professionals are as impressed as other members of the scientific and technological elite of developing countries by the ingenuity and elegance of certain

10 A number of such changes is being considered in broadcasting training in Algeria at the moment in the context of general experiments with technical institutes in various fields since 1971. Interview with Director of Personnel and Training, Radio-Télévision Algérienne, March 1974. 
types of very expensive gadgets. For many professionals in this situation the sophistication of the equipment and materials with which they work is a measure of their professional qualities, their professional 'development'. They share the scientific value system of the international community to which they belong, which may lead them to be entirely out of step with the priorities, demands or available finance for imported capital intensive equipment within their own country. Professionalism of this kind, often engenders expenditure on systems or equipment which put a heavy strain on the limited budget of a system intended for national coverage, or assistance in the diffusion of national goals.

Changing the nature of professionalism in the society involves changes in social objectives and rewards which are traditionally in conflict with scientific ones. An interesting example of a challenge to the traditional professional mode is to be found in China, where polyvalence in training and a circulation of professional personnel throughout its broadcasting organizations, as well as the development of relatively simple technologies which can be used by personnel with relatively little training, have become a dominant part of the operation of broadcasting (Smythe in Gerbner et al. eds. 1973). Challenging questions can be asked about the relevance of such models of technology, training or professionalism in another context.

The Sources and Uses of Aid, Technology and Private Investment Very often mass communications in general or broadcasting in particular have received a fairly low aid priority, or have been linked to favourable trade terms or export incentives for private investors from principal donor countries. By default, therefore, private investors and multinational corporations have dominated the field, often unhindered by alternative expertise recruited through aid agencies. This has had a considerable effect recently in some countries (in Jordon and Ethiopia, notably), where specialists in educational broadcasting, now recognised as a more important aid priority than before, found it difficult to adapt the methods of operation established by the commercial firms, which set up television in many countries in the Middle East and Africa" $"$ to educational needs. With

11 Interview at the Centre for Educational Development Overseas, London, April 1974. 
scarce personnel and a need for speed of operation, the question of retraining and rethinking poses itself. Retraining of production staff and the conversion of inadequate facilities towards making more local programmes involves a great cost to small local broadcasting authorities.

Examining the relationship between principal aid donors and major firms operating in the field would illuminate the extent to which active co-operation between them may increase the quantity of equipment available to recipient countries but may also tie them to particular kinds of equipment (outdated in some cases) or equipment packages. ORTF, for example, has recently participated in the formation of an organization (SOFRATEV) which will encourage the sale of French-made equipment and material in the Middle East and elsewhere ${ }^{12}$, thus linking its broadcasting authority to the promotion of goods from private manufacturers, and duplicating the already successful operation of American firms in the market. In recipient countries political decisions are very often linked with decisions on the availability of technologies to further constrain broadcasting potential. That is, the choice of a particular system or type of equipment for broadcasting may be a fairly low priority for the local government and accepted as the spin-off of another import, such as a military communications system.

In a situation where the most qualified personnel have been purchased out of the competitive market by the major firms the number of personnel in developing countries qualified to evaluate a contract or a choice of technology is very limited. Thus the confrontation of unequals is aggravated by the specialized and relatively recent nature of the field. Several large countries in Latin America and Asia and groups of countries in Africa are now presented with the possibility of satellite broadcasting, either through the international private system, Intelsat, or various national or regional systems for educational purposes. The eve of this leap to a new dimension is perhaps an opportune time to try to consolidate available information as well as to make a critical assessment of aid and assistance programmes in broadcasting and the activities of the various major firms.

12 Interview at the Service de la Recherche, ORTF, Paris, April 1974. 
Any study of the 'expertise constraint' in post-negotiations would, it is hoped, alert actual and potential decision-makers in developing countries to the nature of the problem and perhaps point out possible solutions - for example the pooling of information through regional organizations, or the development by international bodies of an advisory service to supplement the expertise available to individual countries.

\section{Towards a National Broadcasting Policy}

To develop an understanding of the international context of broadcasting is to serve the interests of policy-makers, broadcasters and educationalists in developing countries. But in the national context, whose interest do they serve? In order to establish more direct contributions to communications policy, it would be necessary to consider the capacity of broadcasting to assist the incorporation of various communities and groups in the society, that is, to attempt to reverse the process of marginalization of poor and other groups. The capacity of the system to respond to the needs of different groups is a measure of its effectiveness in using broadcasting as a two-way process rather than a one-way process of direction and control established at the top. Its capacity to encourage an equitable distribution of the educational, informational and cultural benefits of the nation is a measure of its effectiveness. Flexibility in the administration of broadcasting and the imagination of its administrators and broadcasters are the measures of its development as a system, not the amount of complicated and expensive hardware available or its capacity to broadcast via satellite. Insofar as broadcasting is used exclusively as a means of control by the ruling elite, insofar as it is used as an instrument of class domination, its capacity to engage the nation in the development process is lost. An awareness of the external constraints and a positive attempt to maintain national control for national purposes requires careful consideration of its internal goals.

\section{References}

Gerbner, G., 1969, 'Institutional Pressures upon Mass Communications' in P. Halmos, ed. The Sociology of Mass Media Communications, The Sociological Review Monographs, 13, University of Keele, Keele. 
Golding, Peter, and Elliot, Philips, 1974, 'Mass Communication and Social Change: the Imagery of Development and the Development of Imagery' in E.J. de Kadt, ed. Sociology and Development, Tavistock, London.

Katz, Elihu, 1973, 'Television as a Horseless Carriage' in G. Gerbner et al, eds. Communications Technology and Social Policy: understanding the new 'cultural revolution', a Wiley-Interscience Publication, New York.

Lerner, D., 1958, The Passing of Traditional Society, Modernizing the Middle East, Free Press, New York.

Nasamiento, C., 'The Menace of the Mass Media', New Internationalist, September 1973.

Rogers, E., and Svenning, L., 1969, Modernization among Peasants: the Impact of Communication, Holt, New York.

Smythe, D.W., 1973, 'Mass Communications and Cultural Revolution: the Experience of China' in G. Gerbner et al. eds. Communication Technology and Social Policy: understanding the new 'cultural revolution', Wiley, New York. 